\title{
Obvious but Always Ignored: Nutritional Status Affects Cardiac Surgery Mortality
}

\author{
Arif Gucu ${ }^{1}$, Ozlem Arican Ozluk ${ }^{1}$, Sadik Ahmet Sunbul ${ }^{1}$, Nail Kahraman ${ }^{1}$, Deniz Demir ${ }^{1}$, \\ Ibrahim Burak Seker ${ }^{1}$, and Ayse Sunbul ${ }^{1}$ \\ ${ }^{1}$ Bursa Yuksek Ihtisas Training and Research Hospital
}

January 31, 2021

\begin{abstract}
Background: The nutritional status of the patient is an important parameter in patients undergoing surgery. This study aims to determine of prognostic nutritional index value that predicts hospital mortality and morbidity in on-pump cardiac surgery. Methods: In this study, we scanned the medical data of 1003 patients who underwent on-pump cardiac surgery. Patients' divided into two groups according to in-hospital mortality. 934 patients without in-hospital mortality were defined as Group I, and 69 patients who died in the hospital were defined as Group II. Their preoperative nutritional status was determined using the prognostic nutritional index classification. Results: In our series, age is statistically higher in Group II rather than Group I $(62.5 \pm 0.3$ vs. $67.4 \pm 1.2 ; \mathrm{p}=0.001)$. There was a significantly different a higher tendency of hospital-acquired infection in Group II ( $151 ; 16.2 \%$ vs. $44 ; 63.8 \% ; \mathrm{p}=0.001)$. Postoperative stroke significantly higher in Group II $(35 ; 3.7 \%$ vs. $62 ; 89.9 \%$; $\mathrm{p}=0.001)$. Multivariate analysis revealed that cross clamp time, cardiopulmonary bypass time, intraaortic balloon pump usage and intensive care unit stay significantly higher in Group II ( $<<0.05$, respectively). The prognostic nutritional index value was found statistically low in Group II (48.34 \pm 6.71 vs. $44.76 \pm 7.63 ; \mathrm{p}=0.001)$. Multivariate analysis revealed that male gender, age, and the prognostic nutritional index were independently associated with postoperative survival. Conclusion: In on-pump cardiac surgery, postoperative mortality and morbidity are significantly associated with preoperative low prognostic nutritional index, and the prognostic nutritional index can be a useful and suitable parameter for preoperative risk evaluation.
\end{abstract}

\section{INTRODUCTION}

Despite recent advance in technology and surgical techniques, the perioperative and in-hospital mortality and morbidity rates of patients undergoing cardiac surgery remain high ${ }^{1-3}$. There are many factors that can cause this increase in risk. Left ventricular dysfunction, preoperative anemia, chronic renal failure, coronary artery diameter and advanced age are the most common causes ${ }^{4-8}$. Currently, various risk estimation algorithms are used to evaluate the surgical risk of patients planned for cardiac surgery. The most commonly used of these are the Society of Thoracic Surgeons (STS) score and the Euroscore ${ }^{9,10}$. While both scores take into account many variables belonging to the patient, they ignore the clinical nutritional status of the patient. On the other hand, the patient's clinical nutritional status is an indirect indicator of the patient's resistance and reservoir. This relationship has been demonstrated especially in patients undergoing gastrointestinal system and malignancy surgery ${ }^{11,12}$. Several different methods, including Mini Nutritional Assessment, Malnutrition Universal Screening Tool, Subjective Global Assessment, and Short Nutritional Assessment Questionnaire have been developed for the nutritional status of patients who undergo malignancy surgery. The prognostic nutritional index (PNI) is one of them, and it's the most widely used method. The PNI, which was first designed by Buzby et al. ${ }^{11}$ in 1980 and simplified by Onodera et al. ${ }^{13}$, was calculated based on the serum albumin concentration and lymphocyte count of peripheral blood. On the other hand, there are very limited studies in the literature regarding this evaluation in patients undergoing cardiac surgery ${ }^{14}$. Thus the aim of this study was to assess the value of PNI as a predictor of in hospital mortality and morbidity in patients 
undergoing cardiac surgery.

\section{MATERIALS AND METHODS}

This retrospective study included a total of 1003 patients who underwent on-pump cardiac surgery in our institute between January 2016 and January 2020. The patients' demographic characteristics, medical records, laboratory study findings, and clinical outcomes were retrospectively collected by searching the institutional clinical database. Surgical procedures included coronary artery bypass grafting (CABG), aortic valve replacement (AVR), mitral valve replacement (MVR), and combined procedures (Table1). Peripheral blood samples taken on the first day of hospitalization for all patients were noted. The whole blood cell count analysis were performed using Beckmann Coulter LH780 Hematology Analyzer device and Biochemical measurements were performed using Roche diagnostic Cobas 8000 (Manheim).

Other data, body mass index (BMI), preoperative left ventricular ejection fraction (LVEF), cross clamp (X-clamp) time, cardiopulmonary bypass (CPB) time, intraaortic balloon pump (IABP) usage, intensive care unit (ICU) stays, postoperative hospital-acquired infection and stroke were noted. We defined six types of infections after cardiac surgery as hospital-acquired infections Based on O'Keefe et al. ${ }^{15}$. These included urinary tract infection, pneumonia, harvest site infections, superficial sternal wound infection, deep sternal wound infection, and sepsis. We also noted that stroke events after surgery. The most commonly used definitions were stroke observed 'on waking' or 'after extubation' for early stroke after a symptom-free interval for delayed stroke. We used both to describe postoperative stroke.

The preoperative nutritional status of the patients was assessed using the PNI classification. PNI was calculated according to the formula: $10 \mathrm{x}$ serum Albumin $+0.005 \mathrm{x}$ total lymphocyte count (as previously described $)^{13}$.

The study protocol was approved by the Bursa Yuksek Ihtisas Training and Research Hospital Ethics Committee (2011-KAEK-25 2020/03-11). The informed consent requirement was renounced due to the retrospective nature of the study.

Statistical Analysis

Continuous study data were presented as the mean \pm Standard deviation. Categorical variables were presented as the number and percentage. To compare the severity of each symptom between the groups with respect to continuous variables was tested with Student's t-test or Mann-Whitney U test, with the former being used for normally distributed variables and the latter for non-normally distribute dones. The difference with regard to categorical variables was tested using the chi-squared test. To determine potential risk factors for preoperative mortality, multivariable logistic regression analysis was performed. All statistical analyses were performed using SPSS package for Windows version 21 (SPSS Inc., Chicago, IL, USA). For all statistical analyses, p-value of $<0.05$ was considered statistically significant.

\section{RESULT}

The overall study consisted of 1003 patients; a mean age of $62.9 \pm 10.8$ years, of whom $755(75.3 \%)$ were male and $248(24.7 \%)$ were female. Hypertension was the most identified risk factor in 452 patients $(45.1 \%)$, and 279 of all patients $(27.8 \%$ ) had diabetes mellitus. In-hospital mortality occurred in 69 patients $(6.87 \%)$.

Patients were divided into two groups according to in-hospital mortality. 934 patients without in-hospital mortality were defined as Group I, and 69 patients who died in the hospital were defined as Group II. Compared to Group I, Group II patients were significantly older $(62.5 \pm 10.8$ vs. $67.45 \pm 10.1, \mathrm{p}=0.001)$. Comparisons of the groups with respect to the laboratory data revealed that Group II had significantly lower hemoglobin levels, albumin levels, $(\mathrm{p}=0.001)$. Preoperative serum creatinine levels were significant differences between Group I and Group II ( $1.0 \pm 0.02$ vs. $1.3 \pm 0.1 ; \mathrm{p}=0.01$, respectively). Compared to Group I, PNI level was significantly lower in the Group II (48.34 \pm 6.71 vs. $44.76 \pm 7.63$, respectively, $\mathrm{p}=0.001)$. The mean BMI was similar between the groups $(26.70 \pm 2.87$ vs. $26.54 \pm 2.60 \mathrm{p}=0.66)$. Preoperative LVEF was statistically lower in the Group II rather than the Group I ( $51.6 \pm 0.3$ vs. $44.5 \pm 1.2 ; \mathrm{P}=0.001)$. Since the 
infection was broadly categorized in our study, we compared hospital-acquired infection between groups. There was a significantly different a higher tendency of hospital-acquired infection in the Group II (151; $16.2 \%$ vs. $44 ; 63.8 \% ; \mathrm{p}=0.001)$. Postoperative stroke significantly higher in the Group II $(35 ; 3.7 \%$ vs. 62 ; 89.9\%; $\mathrm{p}=0.001)$. Multivariate analysis revealed that $\mathrm{X}$-clamp time $(\mathrm{p}<0.005)$, CPB time $(\mathrm{p}=0.001)$, IABP usage $(\mathrm{p}=0.001)$, and ICU stay $(\mathrm{p}=0.001)$ significantly higher in the Group II.

The demographic, clinical, echocardiographic, biochemical data of the two groups were shown in Tables 2 and 3 .

In the receiver-operating characteristic analysis, PNI lower than 42.6 predicted in-hospital mortality with $82 \%$ sensitivity and $42.6 \%$ specificity [area under the curve $0.64,95 \%$ confidence interval $0.572-0.714 ; \mathrm{p}=0.001$ ] (Figure1). Multivariate analysis revealed that male sex (95\% confidence interval $1.29-11.91, \mathrm{p}=0.016)$, age (95\% confidence interval $1.11-10.15, \mathrm{p}=0.032)$, and the PNI ( $95 \%$ confidence interval $0.18-0.90, \mathrm{p}=0.026$ ) were independently associated with postoperative survival.

\section{CONCLUSION}

The European Society for Clinical Nutrition and Metabolism defined malnutrition as a condition resulting from a lack of nutrition or intake that leads to changes in body composition (reduction of lean mass) and body cell mass, resulting in reduced physical and mental function and impaired clinical outcomes from the disease. Additionally, cardiac cachexia triggers impaired neuroendocrine and immunological function, and it is considered an indicator of poor prognosis regardless of age and disease severity ${ }^{16,17}$.

Malnutrition is generally associated with humoral and cellular immune dysfunction, inflammatory response change, and the wound healing process delay or failure. It is well known that malnutrition is closely related to the incidence of postoperative complications, length of hospital stay, quality of life, and increased mortality of malignant tumors ${ }^{18}$. Besides, the negative impact of long-term calorie and protein deficiencies on critically ill surgical patients' outcomes has recently been demonstrated ${ }^{19}$. The decreased response of albumin and lymphocytes to acute disease indicates low immunonutritional status. The PNI was calculated based on the serum albumin concentration and lymphocyte count of peripheral blood. Therefore, the PNI score should be considered a clinical element and indicator of disease severity in patients undergoing cardiac surgery. Some studies recently reported that a lower PNI level was significantly associated with higher mortality in patients with cardiovascular diseases ${ }^{20-23}$. One of the most beneficial aspects of PNI is not time-consuming, and no special equipment is required. Therefore, it can be easily integrated into routine clinical practice. Although the prognostic significance of the PNI has been reported previously in several types of abdominal or gastrointestinal surgery, its relevance in cardiovascular surgery has not been proven. The surgery's success depends not only on technical surgical skills but also on the preoperative nutritional status.

Keskin et al. ${ }^{24}$ showed a significant relationship between PNI level and mortality (in-hospital and long-term) in coronary artery disease patients undergoing CABG. In addition, Hyashi et al. ${ }^{25}$ retrospective study showed that a high PNI value was found to decrease mechanical ventilation duration, ICU stays, and infection rates. In the multivariate analysis, in addition to age and female gender, a low PNI value was determined as an independent predictor for mortality. Recent published Lee et al. ${ }^{26}$ study is the first to assess the usefulness of the PNI in adult cardiac surgery using only CPB and showed that a lower PNI was an independent predictor of early morbidity and mortality, and was also related to prolonged mechanical ventilation support and ICU stays.

In cardiac surgery, an increasing number of older people are accepted for elective surgery. When low preoperative PNI is detected in elderly patients, postoperative nutritional management such as serum albumin supplementation, dietary maintenance, or nutritional supplementation should be considered to improve patients' nutritional status ${ }^{27}$.

Our research demonstrated that the PNI value was statistically low in the mortality group. There was significantly different a higher tendency for postoperative hospital-acquired infection and stroke in the mortality group. PNI may be used to predict patients' outcomes before cardiac surgery and select an adequate surgical 
strategy. In that case, it must be useful for choosing the biological or mechanical materials for valvular surgery and determining graft materials in coronary surgery. In the case of patients with a low PNI, less invasive surgery may be suitable if possible.

Our study does not include the effects of preoperative nutritional support on postoperative mortality and morbidity in patients with low PNI values. Further studies are needed to show the results of preoperative nutritional support in elective cases.

Preoperative low PNI level was evaluated as an independent predictor of long-term cardiovascular outcomes. Also, it was statistically significantly associated with postoperative mortality and morbidity in cardiac surgery. According to the results we obtained in our study, we firmly believe that PNI is a useful and suitable parameter for preoperative assessment of nutritional status and should be regarded in managing the indication and strategy in on-pump cardiac surgery.

Authors' contributions The authors' responsibilities were as follows: AG, OAO and SAS conceived the study and designed the search strategy; AG and OAO conducted the study selection; SAS and NK conducted data extraction; AG, NK and DD evaluated the risk of bias of included studies; AG, OAO and SAS conducted the data analysis and interpretation of results; AG, OAO and IBS wrote the first draft of the manuscript; AG and OAO revised the manuscript; all authors read and approved the final version of the manuscript.

\section{Acknowledgments}

We would like to thank the Bursa Yuksek Ihtisas Research and Training Hospital cardiovascular surgery team for all these operations.

\section{REFERENCES}

1. Hannan EL, Racz MJ, Walford G, Jones RH, Ryan TJ, Bennett E, et al. Long-term outcomes of coronary-artery bypass grafting versus stent implantation. N Engl J Med. 2005 May 26;352(21):217483. doi: 10.1056/NEJMoa040316. PMID: 15917382.

2. Birkmeyer JD, Siewers AE, Finlayson EV, Stukel TA, Lucas FL, Batista I, et al. Hospital volume and surgical mortality in the United States. N Engl J Med. 2002 Apr 11;346(15):1128-37. doi: 10.1056/NEJMsa012337. PMID: 11948273.

3. Ribeiro AL, Gagliardi SP, Nogueira JL, Silveira LM, Colosimo EA, Lopes do Nascimento CA. Mortality related to cardiac surgery in Brazil, 2000-2003. J Thorac Cardiovasc Surg. 2006 Apr;131(4):907-9. doi: 10.1016/j.jtcvs.2005.11.022. PMID: 16580451.

4. Fortescue EB, Kahn K, Bates DW. Development and validation of a clinical prediction rule for major adverse outcomes in coronary bypass grafting. Am J Cardiol. 2001 Dec 1;88(11):1251-8. doi: 10.1016/s0002-9149(01)02086-0. PMID: 11728352.

5. Kulier A, Levin J, Moser R, Rumpold-Seitlinger G, Tudor IC, Snyder-Ramos SA, et al. Investigators of the Multicenter Study of Perioperative Ischemia Research Group; Ischemia Research and Education Foundation. Impact of preoperative anemia on outcome in patients undergoing coronary artery bypass graft surgery. Circulation. 2007 Jul 31;116(5):471-9. doi: 10.1161/CIRCULATIONAHA.106.653501. Epub 2007 Jul 9. PMID: 17620512.

6. Cooper WA, O'Brien SM, Thourani VH, Guyton RA, Bridges CR, Szczech LA, et al. Impact of renal dysfunction on outcomes of coronary artery bypass surgery: results from the Society of Thoracic Surgeons National Adult Cardiac Database. Circulation. 2006 Feb 28;113(8):1063-70. doi: 10.1161/CIRCULATIONAHA.105.580084. Epub 2006 Feb 20. PMID: 16490821.

7. O'Connor GT, Morton JR, Diehl MJ, Olmstead EM, Coffin LH, Levy DG, et al. Differences between men and women in hospital mortality associated with coronary artery bypass graft surgery. The Northern New England Cardiovascular Disease Study Group. Circulation. 1993 Nov;88(5 Pt 1):2104-10. doi: 10.1161/01.cir.88.5.2104. PMID: 8222104.

8. Daly LE, Lonergan M, Graham I. Predicting operative mortality after coronary artery bypass surgery in males. Q J Med. 1993 Dec;86(12):771-8. PMID: 8108535. 
9. Hattler BG, Madia C, Johnson C, Armitage JM, Hardesty RL, Kormos RL, et al. Risk stratification using the Society of Thoracic Surgeons Program. Ann Thorac Surg. 1994 Nov;58(5):1348-52. doi: 10.1016/0003-4975(94)91911-9. PMID: 7979657.

10. Nashef SA, Roques F, Michel P, Gauducheau E, Lemeshow S, Salamon R. European system for cardiac operative risk evaluation (EuroSCORE). Eur J Cardiothorac Surg. 1999 Jul;16(1):9-13. doi: 10.1016/s1010-7940(99)00134-7. PMID: 10456395.

11. Buzby GP, Mullen JL, Matthews DC, Hobbs CL, Rosato EF. Prognostic nutritional index in gastrointestinal surgery. Am J Surg. 1980 Jan;139(1):160-7. doi: 10.1016/0002-9610(80)90246-9. PMID: 7350839 .

12. Iwasa M, Ogoshi S, Kitagawa S, Ohmori Y, Iwasa Y, Mizobuchi S, et al. Effect of Preoperative Hyperalimentation for Patients with Esophageal Cancer and Usefulness of the NutritionalAssessment Index. In: Siewert JR, Hölscher AH, eds. Diseases ofthe Esophagus. Berlin: Springer; 1988. pp. 264-7.

13. Onodera T, Goseki N, Kosaki G. Prognostic nutritional index in gastrointestinal surgery of malnourished cancer patients. Nihon Geka Gakkai Zasshi. 1984 Sep;85(9):1001-5. Japanese. PMID: 6438478.

14. Kurumisawa S, Kawahito K. Risk analysis using the prognostic nutritional index in hemodialysisdependent patients undergoing cardiac surgery. J Artif Organs. 2018 Dec;21(4):443-449. doi: 10.1007/s10047-018-1056-z. Epub 2018 Jun 27. PMID: 29951931.

15. O'Keefe S, Williams K, Legare JF. Hospital-Acquired Infections After Cardiac Surgery and Current Physician Practices: A Retrospective Cohort Study. J Clin Med Res. 2017 Jan;9(1):10-16. doi: 10.14740/jocmr2637w. Epub 2016 Nov 24. PMID: 27924169; PMCID: PMC5127209.

16. Cederholm T, Barazzoni R, Austin P, Ballmer P, Biolo G, Bischoff SC, et al. ESPEN guidelines on definitions and terminology of clinical nutrition. Clin Nutr. 2017 Feb;36(1):49-64. doi: 10.1016/j.clnu.2016.09.004. Epub 2016 Sep 14. PMID: 27642056.

17. Anker SD, Coats AJ. Cardiac cachexia: a syndrome with impaired survival and immune and neuroendocrine activation. Chest. 1999 Mar;115(3):836-47. doi: 10.1378/chest.115.3.836. PMID: 10084500.

18. Morgan TM, Tang D, Stratton KL, Barocas DA, Anderson CB, Gregg JR, et al. Preoperative nutritional status is an important predictor of survival in patients undergoing surgery for renal cell carcinoma. Eur Urol. 2011 Jun;59(6):923-8. doi: 10.1016/j.eururo.2011.01.034. Epub 2011 Jan 28. PMID: 21295907; PMCID: PMC3085569.

19. Yeh DD, Fuentes E, Quraishi SA, Cropano C, Kaafarani H, Lee J, et al. Adequate Nutrition May Get You Home: Effect of Caloric/Protein Deficits on the Discharge Destination of Critically Ill Surgical Patients. JPEN J Parenter Enteral Nutr. 2016 Jan;40(1):37-44. doi: 10.1177/0148607115585142. Epub 2015 Apr 29. PMID: 25926426.

20. Basta G, Chatzianagnostou K, Paradossi U, Botto N, Del Turco S, Taddei A, et al. The prognostic impact of objective nutritional indices in elderly patients with ST-elevation myocardial infarction undergoing primary coronary intervention. Int J Cardiol. 2016 Oct 15;221:987-92. doi: 10.1016/j.ijcard.2016.07.039. Epub 2016 Jul 6. PMID: 27441479.

21. Keskin M, Hayıroğlu MI, Keskin T, Kaya A, Tatlısu MA, Altay S, et al. A novel and useful predictive indicator of prognosis in ST-segment elevation myocardial infarction, the prognostic nutritional index. Nutr Metab Cardiovasc Dis. 2017 May;27(5):438-446. doi: 10.1016/j.numecd.2017.01.005. Epub 2017 Jan 18. PMID: 28392077.

22. Hayıroğlu MI, Keskin M, Keskin T, Uzun AO, Altay S, Kaya A, et al. A Novel Independent Survival Predictor in Pulmonary Embolism: Prognostic Nutritional Index. Clin Appl Thromb Hemost. 2018 May;24(4):633-639. doi: 10.1177/1076029617703482. Epub 2017 Apr 12. PMID: 28401800; PMCID: PMC6714701.

23. Ozluk OA, Akdeniz A, Guclu E, Tuncay B, Bozat T. The Usual Suspects' but Always Ignored: The Nutritional and Immune System's Status Affect the Infective Endocarditis Hospital Mortality. International Journal of Immunology. Vol. 8, No. 1, 2020, pp. 9-12. doi: 10.11648/j.iji.20200801.12

24. Keskin M, İpek G, Aldağ M, Altay S, Hayıroğlu MI, Börklü EB, et al. Effect of nutritional status on mortality in patients undergoing coronary artery bypass grafting. Nutrition. 2018 Apr;48:82-86. doi: 10.1016/j.nut.2017.10.024. Epub 2017 Dec 7. PMID: 29469026. 
25. Hayashi J, Uchida T, Ri S, Hamasaki A, Kuroda Y, Yamashita A, et al. Clinical significance of the prognostic nutritional index in patients undergoing cardiovascular surgery. Gen Thorac Cardiovasc Surg 68, 774-779 (2020). https://doi.org/10.1007/s11748-020-01300-x

26. Lee SI, Ko KP, Choi CH, Park CH, Park KY, Son KH. Does the prognostic nutritional index have a predictive role in the outcomes of adult cardiac surgery? J Thorac Cardiovasc Surg. 2020 Jul;160(1):145153.e3. doi: 10.1016/j.jtcvs.2019.08.069. Epub 2019 Sep 19. PMID: 31627943.

27. Alexander KP, Newby LK, Cannon CP, Armstrong PW, Gibler WB, Rich MW, et al. Acute coronary care in the elderly, part I: Non-ST-segment-elevation acute coronary syndromes: a scientific statement for healthcare professionals from the American Heart Association Council on Clinical Cardiology: in collaboration with the Society of Geriatric Cardiology. Circulation 2007; 115(19): 2549-69.

Table 1. The type of the surgical procedures according to groups

Type of the surgical procedure

CABG (n, \%) CABG+AVR (n, \%) CABG+MVR (n, \%) CABG+AVR+MVR (n, \%) AVR (n, \%) MVR (n, \%) AVR+MVH

CABG: Coronary artery bypass grafting, AVR: Aortic valve replacement, MVR: Mitral valve replacement

Table 2. Comparison of basic blood values of patients in groups

Basic Blood Values

Hemoglobin $(\mathrm{gr} / \mathrm{dL})$ WBC $\left(\mathrm{x} 10^{3}\right)$ Neu $\left(\mathrm{x} 10^{3}\right)$ Lym $\left(\mathrm{x} 10^{3}\right)$ Platelets $\left(\mathrm{x} 10^{3}\right)$ CRP $(\mathrm{mg} / \mathrm{dL})$ Cre $(\mathrm{mg} / \mathrm{dL})$ Total Protein $(\mathrm{g} / \mathrm{d}$

WBC: White blood cell, Cre: Creatinine, Neu: Neutrophil, Lym: Lymphocyte, Crp: C-reactive protein

*the mean difference is significant at the 0.05 level

Table 3. Comparison of Characteristics and Basic Findings of patients in groups

Characteristics and Basic Findings

Male (n,\%) Age (year) Preoperative LVEF (\%) BMI ( $\left.\mathrm{m}^{2} / \mathrm{kg}\right)$ X-clamp time (min) CPB time (min) IABP usage (n,\%) ICU

LVEF: Left ventricular ejection fraction, X- clamp: Cross clamp, CPB: Cardiopulmonary bypass, IABP: Intraaortic balloon pump, ICU: Intensive care unit

*the mean difference is significant at the 0.05 level

Figure1. Data figure of the area under the curve (AUC), confidence interval (CI), and cut-off values in receiver-operating characteristic (ROC) curve analysis for prognostic nutritional index.

\section{Hosted file}

FIGURE 1.pdf available at https://authorea.com/users/392914/articles/506660-obvious-butalways-ignored-nutritional-status-affects-cardiac-surgery-mortality 